doi: $10.5007 / 1808-1711.2012 v 16 n 2 p 209$

\title{
Universalizing Hermeneutics as Hermeneutic Realism
}

\author{
Dimitri GineV \\ University of Sofia
}

\begin{abstract}
This article explores and attempts to resolve some issues that arise when at stake is the incommensurability between the concepts of reality developed by philosophical hermeneutics, on the one hand, and realist branches of analytical philosophy, on the other. The view of hermeneutic realism is suggested not as a remedy against this incommensurability, but as a vehicle for revising those aspects of both hermeneutics and ontological realism which impede the dialogue between them. It is a view that opposes epistemological foundationalism, Cartesian dualism, essentialism about theoretical objects, and cognitive relativism. The role of reading/textualizing in science's spaces of representation is specified.
\end{abstract}

Keywords: Hermeneutic realism; phronesis-rationality; strong holism; situated transcendence; trans-subjectivity.

\section{Realism Without Essentialism}

The realism-antirealism debate has strengthened the belief that each version of realism in philosophy must carry with it a commitment to a certain range of entities which is specified by assuming a reality that is present-at-hand. The very specification of entities of a given kind would imply the adherence to an essentialist position: There is a class of (mathematical, linguistic, physical, social, cultural or whatever) entities whose existence is reified as something "given", as presence-at-hand. Prominent examples in this regard are the reification of unobservable entities posited by the successful scientific theories, and the hypostatization of theories' basic mathematical structures that get retained across global theory change. Metaphysical realism, scientific realism, structural realism, and even Hacking's "entity realism" and Putnam's "internal realism" cannot avoid the pitfall of essentialist reification. Is it possible a kind of "realism without essentialism"? In posing this question, I take the notion of "essentialism" to be opposed first and foremost not to radical internalism (à la Arthur Fine) or to deflationism (à la Joseph Rouse) or to neopragmatist "epistemological behaviorism" (à la Richard Rorty). In all these cases only particular aspects of essentialism are countered. Thus, Rorty criticizes predominantly the representationalist aspect of essentialism as an epistemological doctrine (see, for instance, Rorty 2007). Fine's NOA is an anti-essentialist position concerning the issues of aim of science, scientific truth, explanation, justification, and rationality (see Fine 1986, pp. 112-35). Rouse undertakes an extension of Fine's anti-essentialism by drawing

Principia 16(2): 209-227 (2012).

Published by NEL — Epistemology and Logic Research Group, Federal University of Santa Catarina (UFSC), Brazil. 
consequences from NOA for a social-political criticism of the essentialist interpretations of scientific knowledge. In so doing, Rouse tries to enrich anti-essentialism with contextualist transcendental arguments (see Rouse 1996, pp. 90-101).

In this paper, I will use the term of "existentialism" to refer to a view that opposes essentialism in the totality of its aspects. In contrast to the views indicated above, existentialism is not a particular form of anti-essentialism, but a kind of global antiessentialism. ${ }^{1}$ On the doctrine of "realism without essentialism", the reality must be comprehended in an existentialist manner. My aim is to make the case that the doctrine in question is realism about the reality that is ready-to-hand within the "readable technologies" of interrelated practices. ${ }^{2}$ This realism would specify not a range of entities but the conditions under which one would be able to take (within the interrelatedness of practices) an objectifying attitude concerning entities of a given type, thereby laying claim about the reality of these entities as an objective presence-athand. By posing the question of the possibility of objectifying attitudes, the realist view being under discussion would serve a transcendental function regarding the study of the possibility of realist positions on ontical level. In other words, this would be a kind of "critical realism" in double sense. On the one hand, it is "critical" in Kantian sense as a view that asks about conditions of possibility. On the other, it criticizes each essentialist reification and hypostatization of entities.

Hermeneutic realism demands also an anti-essentialist stance with regard to science's theoretical objects. In other words, in formulating criteria for existence of these objects, one has to avoid essentialist assumptions that associate the theoretical objects with physical or formal structures cast in terms of invariant presence. The hermeneutic realist argues that science's theoretical objects are neither entities-inthemselves nor entities postulated by theories that are useful intellectual fictions. These objects rather exist through their visualizabilty within deferring spaces of representation. Following this line of argument, it will be held that within the deferring spaces of representation a theoretical object is scattered in potentially endless "traces". At the same time, what gets textualized and represented is used as a tool of intervening in the next stages of the research process that articulates an autonomous scientific domain.

In breaking in a radical manner with the "myth of the Given", the hermeneutic realist holds that there is no "access" to reality but through the interrelatedness of practices. By implication, the reality investigated by science is the reality that is ready-to-hand within the interrelatedness of scientific practices. This view, however, does not imply that the reality is constructed by scientific practices. Putting scientific practices first is not a kind of constructivism. It means rather that the meaning of reality is disclosed by these practices. On the existentialist tenet of hermeneutic realism, there is no reality without meaning. Hermeneutic realism is realism about the reality-with-meaning disclosed by interrelated practices.

Principia 16(2): 209-227 (2012). 
Starting out from the ways of being in the world of practices prevents one from an initial hypostatization of a dualism between the epistemic subject and the objective world (and the dualism of conceptual framework and empirical content). The entangled participation in the world of practices is an interpretative mode of being in the world. Human beings are interpreting themselves in accordance with the possibilities they can appropriate and actualize in this involvement. In so doing, they are also interpreting the world of practices within the horizon of possibilities they have at their disposal. Being in the world of practices amounts to interpreting the world (and one's involvement in it) as a world projected upon possibilities that are engendered by the very interrelatedness of practices. On hermeneutic realism, the "horizon of understanding the world" (as a prerequisite for having an objective knowledge about the world) is tantamount to the "world as a horizon of understanding". Thus, the hermeneutic circularity is to be ascribed not only to interpretation as a particular cognitive procedure, but first and foremost to the being of human existence as being in the world of practices.

Hermeneutic realism opposes all views that admit the following clauses: (a) the credentials of all truth claims must be checked by a foundational theory of knowledge; (b) the objective reality is organized into distinct objects, and the distinctness of each of them is prior to the constitution of meaning; (c) the mind of man is isolated from the world in a manner that enables it to represent the world through images, ideas, concepts and categories; (d) there is an invariant and universal semantic core in mind that contains series of meanings related to the basic structure of objective reality. Roughly speaking, hermeneutic realism is a kind of realism that gets rid of Cartesian dualism, epistemic representationalism, foundationalism, and cognitive (including linguistic-semantic) essentialism. It is a common place for those who subscribe to a certain version of hermeneutic philosophy that the world is not out there, and mind is always within the world. Hermeneutic realism is opposed above all to metaphysical realism and by implication to scientific realism. Metaphysical realism is criticized for the uncritical postulation of ontological primacy of the dualism between mind and mind-independent objective reality over the totality of being in the "work-world" of practices, while ignoring at the same time the difference between the ontical and the ontological. The hermeneutic realist raises the critical question of whether mind does not belong to reality. Since most of the metaphysical realists are inclined to argue that mind is a part of objective reality, the hermeneutic realist focuses her criticism on the predicament concerning the reconciliation of the following two doctrines: (i) objective reality is independent of mind; and (ii) mind is part of this reality.

In what follows, the attempt will be made to place the doctrine of hermeneutic realism in a broader philosophical context, confronting it with an established position in the realism-antirealism debate - Hacking's interventionism. On the crit- 
icism I will advance, what is ignored in this position is the way in which there is always meaning constituted before having rationally justified knowledge about particular objects and states of affairs. Actually, hermeneutic realism is not a single doctrine but a family of doctrines that includes core, non-core, and optional doctrines. Among the core-doctrines one has to reckon the hermeneutic construal of the world, the cognitive existentialism about science's theoretical entities, the priority of phronesis-rationality over normative-epistemological rationality, the hermeneutic fore-structuring of the subject-object relationship, the horizonal character of discourse as opposed both to linguistic determinism and linguistic relativism, and the priority of the interpretative openness over the semantic completeness in dealing with the objects of a particular domain. ${ }^{3}$ The burden of my argument is to show that hermeneutic realism does not aim at an anti-epistemology, but rather at a holistic epistemology that is in line with the interpretative theory of the constitution of meaning within-the-world. On this doctrine, by overcoming representational epistemology and discarding any version of naturalized epistemology, one still is able to retain a room for a model-theoretic account of knowledge that has to supplement the constitutional analysis in terms of hermeneutic phenomenology. The semantic completeness of these models, however, is always to be contextualized within the practices of their construction. Hermeneutic realism states that the semantic completeness of each theoretical construction is inevitably relative, while the interpretative openness attributed to its contextualization exceeds constantly this completeness.

\section{Why Not Interventionism}

To begin with, "interventionist realism" (in particular, the version supported by Ian Hacking) should admit that the world is out there as a field of possible interventions effectuated by scientific practices. Hacking's celebrated argument states that the reality of "free quarks" comes into being when physicists are hunting for these entities by inducing fractional charges one niobium ball through spraying it with electrons: "If you can spray them, then they are real." (Hacking 1983, p. 23) More precisely, real are the electrons as tools for intervening in the process of hunting for free quarks: "What convinced me of realism has nothing to do with quarks. It was the fact that by now there are standard ermitters with which we can spray positrons and electrons - and that is precisely what we do with them. We understand the effects, we understand the causes, and we use these to find out something else." (Hacking 1983, p. 24) Accordingly, the mind, which designs practices is not the place of representing what is going on in the world, but a source of constant intervening by means of which what is out there gets provoked. ${ }^{4}$

Yet despite the emphasis on interventions in construing the notion of the world,

Principia 16(2): 209-227 (2012). 
the assumption that the mind (as a designer of practices) is opposed to the world out there remains intact. Thus, there is in interventionist realism a strong commitment to the primacy of the subject-object cut as it is promulgated by the objectivist construal of the world. The main reason for preserving Cartesian dualism intact is the assumption that the mind is working behind the interventions in the world. On this assumption, the hypostatization of the mind is unavoidable.

Hacking is highly successful in combating van Fraassen's view that experimentation is only continuation of theory construction by other means. In asserting that experimentation has a life of its own, however, he legitimizes the dichotomy between theory and experiment. Moreover, his efforts of drawing a sharp dividing line between representing (theorizing) and intervening (experimenting) echo the Kantian dualism of receptivity and spontaneity - a dualism deeply rooted in that philosophy of consciousness, which Hacking presumably tries to overcome. The subsequent distinction between two kinds of realism - realism about entities and realism about theories - is a corollary to the contrast of representing and intervening. Realism about theories presupposes reality as representation. Realism about (theoretical) entities is not merely a side effect or by-product of the presumption that intervention constitutes its own reality. It is rather a viewpoint arising out of the way in which reality as representation is meshing with reality as intervention. On Hacking's conception, natural science since the $17^{\text {th }}$ century has been the adventure of the interlocking of representing and intervening (see Hacking 1983, p. 146).

Hacking's program (from the early 1980s) revolves around the question of which comes first, theory or experiment. Hacking professes (by making use of a wide range of examples from several disciplines) that there is no right answer to this question. I think, however, that he should provide us with a good argument that this is an essentially misleading question. By posing it, one destroys the hermeneutic unity of scientific practices. The dichotomous distinction between representing and intervening does not allow one to see that each scientific practice (in particular, those of experimentation and theory construction) can be carried out by taking into consideration a contextual whole of practices. (The hermeneutic unity being mentioned consists precisely in the circular co-dependence of a contextual whole as a configuration of modeling, formalizing, conceptualizing, experimenting, constructing instruments, etc. and particular practices.) Strangely enough, in all cases of relationship between theory and experimental work Hacking discusses, he establishes not a genetic relation of preceding the former by the latter (or vice versa), but an interplay within a configuration of scientific practices coming from different directions.

Hence, there are good reasons to put the configuration first. In so doing, I will assume that such a configuration consists not only of practices of representing and intervening. There are scientific practices irreducible to (and partially independent of) theorizing and experimentation as well. Examples in this regard are observa- 
tion, designing techniques for graphical representation, different sorts of measuring, construction and calibration of instruments, working on techniques of calculation, elaboration on mathematical formalism, and so on. (Hacking himself pays much attention to the irreducibility of observation to experimentation.) Furthermore, if one goes on to put the configurations of scientific practices first, one would become deprived of a rationale for distinguishing between realism about entities and realism about theories.

On the doctrine of hermeneutic realism, there are practices of representation (and theoretical objectification) and intervention (in particular, experimentation) because the world is always already projected as a horizon of practical constitution of meaning. Hacking correctly states, in my view, that experimenting on an entity does not compel one to believe that the entity exists. Only manipulating an entity in order to experiment on something else can provide a rationale for believing in its existence. ${ }^{5}$ To return to the example, creating experimentally the phenomenon of a beam of electrons by using present electrons proves the existence of the latter. The criterion for existence of a theoretical entity does not amount to identifying something as a pure presence. A theoretical entity obtains a status of reality if and only if it can serve the function of a thing that is ready-to-hand in creating new phenomena. Hacking's realism about entities requires dissolving of any reification of theoretical entities as a presence-in-itself. There is no entity behind or beyond the network of practices creating new phenomena. The view that what is under scientific research keeps always a status of a readiness-to-hand that never becomes a mere presence-at-hand is a core doctrine of hermeneutic realism as well.

Yet what a champion of hermeneutic realism can not accept is Hacking's unwillingness to extend the manipulability-criterion for existence to cover the practices of representing as well. In fact, this unwillingness contradicts Hacking's own view that all reality of representation is involved in practices of representing. He convincingly demonstrates that once there is a practice of representing a second-order (theoretically constructed) concept of reality follows in train. This concept of reality supervenes on the practices of representing, and cannot be disentangled from them. By the same token, a theoretical depiction of a state of affairs achieved by elaborating a system of modeling, structuring, calculating, approximating, etc. does not become isolated from these cognitive practices. Theoretical representation of reality is constantly placed in practical contexts. Depiction through theorizing is only a moment in the stream of practices that serves as a tool for bringing into play new configurations of practices and new spaces of representation. However sophisticated it might be, a theoretical representation does not legitimize a criterion for existence that differs from that related to the creation of new phenomena through manipulating entities that are ready-to-hand. This is why it is an incorrect way of arguing that realism at the level of theory, explanation, predictive success, convergence of

Principia 16(2): 209-227 (2012). 
theories, and so forth is to be locked into reality as representation as opposed to reality as intervention. By undoing the reality-dualism (as a residual Cartesianism) one commits to the view that the world of practices is the reality in which human beings are always already "thrown". This is the reality of ongoing constitution of meaning.

Against the background of the foregoing criticism of Hacking's position, the principal characteristic of the hermeneutic construal of the world I should like to stress in a tentative manner is the commitment to the idea of the transcendence of the world. According to it, human beings, with all cognitive abilities they have, are born and thrown in practices. Yet practices are by no means to be regarded as a reality sui generis. Any reification of them would mean a justification of a new kind of essentialism. Practices in their interrelatedness do not have an existence independent of human beings' thrownness in them. The co-dependence of interrelated practices and the thrownness of practitioners is to be thought on the model of circularity that dissolves any sort of determinism in scrutinizing practical existence. It is the existence as being thrown in practices that has a primacy over the existence authenticated through the emancipation of mental activities by means of which objectification becomes possible. By implication, the construction of representations and images is only a process of being involved in particular cognitive practices mingled with material practices.

To be sure, this construction sometimes requires taking a reflexive distance from the immediate involvement in practices. However, it does not mean abandoning the world of practices. The cognitive construction of epistemic images actually comes into being by transformations within practical existence itself. From this perspective, epistemic images are only tools within practical existence. Furthermore, the distinction between cognitive and material practices, as it was stressed in the foregoing considerations, is solely a conventional one, and does not mark off a philosophically significant demarcation. Human beings are always already operating in the world where material-instrumental, discursive-communicative, symbolic-expressive and cognitive practices are interwoven. Furthermore, practices are organized in coreferential configurations. Being thrown in such configurations amounts to being involved in possibilities for operating within the world. These possibilities are engendered by the very co-referentiality of configurations, which characterizes existence as being thrown in practices. Doubtless, the ways these possibilities come into being are not to be disentangled from practitioners' volitional, cognitive and emotive peculiarities. However, there is a trans-subjective dimension (a dimension related to the world's transcendence of subjectivity) characterizing the constant opening of possibilities within the world - a dimension informed by the interrelatedness of practices.

Thus, the unity of engendering (opening), appropriating and actualizing possi- 
bilities within the world is to be assigned to the circularity between the totality of co-referential configurations of practices and the thrownness of particular practitioners. In another formulation, the unity is rooted in the interplay of the trans-subjective horizons of the world and the empirical dispositions of practitioners as manifested in their situatedness within the world. In fact, the irreducibility of Heidegger's Dasein to an empirical-anthropological complexity is due precisely to the non-eliminability of the trans-subjective dimension, displayed by the ability to understand the world by appropriating possibilities within the world. Thus considered, trans-subjectivity is not to be confused with inter-subjectivity, which is always an empirical phenomenon stemming from actualized possibilities.

In view of the concept of trans-subjectivity developed so far, the following conclusion is to be drawn: existence as being thrown in the world of practices constantly engenders possibilities for operating within this world. The latter are independent of any conscious devising of possibilities for rational behavior, i.e. possibilities stemming from a mental activity that in chalking out such a behavior provides an algorithm of how to choose and appropriate possibilities. The possibilities generated by the interrelatedness of practices are always already projected before those (human beings) involved in the world of practices. Yet at this point again it should be stressed that the possibilities (like practices) do not have an autonomous reality sui generis. Any suggestion of a pure presence of possibilities in existence would rehabilitate essentialism in a new form. They are not independent of the ways of their actualization. More specifically, the projection of possibilities by configurations of interrelated practices is always entangled with choosing and actualizing them. This brings into play another version of the same (hermeneutic) circularity already mentioned.

Being thrown in the world of practices implies that the world transcends each kind of contextual involvement in particular practices (including the kinds of involvement that lead to construction of representations of a world out there). In other words, there is a constant transcendence of the world, persisting in all possible involvements in the contextual configurations of practices. By implication, each particular kind of being in the world of practices is constantly situated within the horizon of possibilities this practical existence (as a kind of being thrown in the world) can appropriate and actualize. "Situated transcendence" is a key figure in the hermeneutic construal of the world. What constantly transcends its situatedness cannot get a stable (not to speak of static) representation. It rather can be represented by a potentially endless chain of deferring spaces of representation. The epistemic cut between subject and object is also situated in the world that transcends the rational organization (in accordance with epistemological norms, standards, and criteria) of the objective knowledge about a thematically given world out there. In other words, each kind of epistemologically (normatively) organized objectifying delimitation of a domain of scientific research takes place in the world of practices. ${ }^{6}$

Principia 16(2): 209-227 (2012). 
Any particular objectification of this kind is due to the actualization of possibilities projected by a particular interrelatedness of practices (say, normal-scientific practices setting up the routine everydayness of a research community). In actualizing possibilities, the particular configurations of practices are at once partially representing theoretical objects and making use of these objects as tools for intervening. (I am saying "partially" because there is a constant deferring of such spaces in the research process that displaces, marginalizes, and hybridizes the transitory pictures of the theoretical objects. "Partially" refers, however, to linkage between representation and reading as well. Since the representation of a theoretical object in a particular setting is the outcome of applying readable technologies, what gets represented is a result of the partial reading that takes place in this setting.)

The interplay of representing-intervening as it is mediated by readable technologies is the theme of the next section.

\section{Representation-through-Visualization and Representation- through-Visualizability}

Thanks to the excellent studies of two historians of science - John Hendry and Arthur Miller - we have now a clear view about the differences between the two fundamental concepts of Heisenberg's epistemology of quantum physics, viz. the concepts of visualization (Anschauung) and visualizability (Anschaulichkeit). My aim in this section is to outline an extended interpretation of visualizability that is fit for the tenets of hermeneutic realism. More specifically, I am going to put forward a concept of visualizability of science's theoretical objects in deferring spaces of representation that is congruent with the hermeneutic construal of the world.

In a non-technical paper on quantum mechanics ("On the intuitive content of the Quantum-Theoretical Kinematics and Mechanics") published in the journal Die Naturwissenschaften Heisenberg raised in 1927 the appeal to free quantum mechanics from the constraint of visual pictures. Heisenberg argues in particular that because of the discreteness of the quantum-mechanical world, a total visualization of its theoretical objects cannot be attained. Here visualization means two things: (a) appropriate visual pictures for quantum mechanics' theoretical objects and (b) an adjustment of these objects' imageries (as determined by theory's formalism) to the intuitive understandings about physical objects. In other words, the "rule of visualization" requires that the theoretical objects' empirical interpretations must have representational (visual) content, and not be counterintuitive. In realizing the impossibility to speak of a monochromatic wave in a very short time interval, and of the position of a particle of fixed velocity, Heisenberg declared the rule of visualization for invalid in atomic physics. According to him, the theoretical objects of the quantum-mechanical world are not to be subjected to this rule of visualizability if

Principia 16(2): 209-227 (2012). 
contradictions were to be avoided. No doubt, Bohr realized as early as in 1913 that there is a need of transferring concepts from classical physics that are represented with images and language anchored in the world of sense perception to a counterintuitive world beyond sense perception. In the following years, many physicists reached the conclusion that the use of visual metaphors that are intuitively justified proved to be inappropriate to the language of atomic physics. (See Miller 1989, p. 326.) The way of realizing the inadequacy of visual imagery based on sense perception precedes the advent of the Copenhagen interpretation of quantum mechanics. (Bohr never gave up the rule of visualization. But in realizing the impossibility of operational definitions of kinematic concepts, he essentially weakened the rule. To a certain extent, the introduction of the principle of complementarity was directly inspired by the requirement that quantum-mechanical description should be in principle consistent with classical visualization.)

The rule of visualization enjoys a large (but not unlimited) validity for the theoretical objects of classical physics. Visualization and visualizability are synonymous in the classical theories. In this case, the mathematical idealizations are designed to permit the description of a physical system through a joint specification of every pair of canonical coordinates. The formalisms of classical physics impose very few restrictions upon the use of visual pictures in the theoretical descriptions of physical systems. The description in that case at once determines and is determined by the rule of visualization. A prerequisite of its validity is that each parameter (variable) of the theoretical description should be measured with arbitrary accuracy that does not depend on measurements of the other parameters. Another prerequisite states that each measurement should be accompanied by an observation. All of the conjugate functions describing theoretically the system's dynamics and all corresponding measurements will respect the commutation rule. In contrast to the wide use of the rule of visualization in classical physics, Heisenberg stresses (especially in his correspondence with Pauli from the late 1920s) an imagery for the quantum-mechanical objects that is entirely determined by the formalism of phase space diagrams. It is the imagery of the cells in a phase space whose shape can be specified, but not their precise location. The position of a fixed cell wall cannot be determined. The visualizabilty through such a diagram is in harmony with the uncertainty relations. This imagery which is also congruent with the kinematic meaning of the matrices cannot be visualized through something that corresponds to sense perception. ${ }^{7}$

Later on, Heisenberg calls "visualizability" the imagery that violates the rule of visualization. A particular dimension of Heisenberg's notion of visualizabilty is that the theory's formalism generates the visual imagery of the atomic world. In analyzing this dimension, Arthur Miller makes the observation that Heisenberg is more engaged not in stressing the counterintuitive character of the quantum-mechanical objects, but in changing the very (in matter of fact, Kantian) concept of intuition 
itself. Important for Heisenberg's epistemological doctrine was the possibility of a non-customary intuition that attributes to the objects of atomic physics a sort of reality that depends on their formal-syntactic (mathematical) representation. Heisenberg went on to claim that one should no longer regard quantum mechanics as unintuitive theory because the concept of intuition had been redefined by the new mathematical formalism. In stressing that visualization and visualizability became for Heisenberg after 1927 mutually exclusive concepts, Miller argues that the epistemological differences between Bohr and Heisenberg rest essentially on the fact that for Bohr the concept of intuition remained connected with that of classical intuition. Heisenberg's non-classical concept of intuition licensed a representation of atomic physics' theoretical objects far beyond the scope of epistemological representationalism.

In employing the new concept of intuition, Heisenberg permitted the theory to interpret only its symbols and not the objects it discussed. This step legitimizes in the final analysis a sort of mathematical essentialism, according to which the syntax of the quantum theory determines its visualizable content that avoids to a maximal extent a direct visual component. In other words, Heisenberg pursued a line of scientific research that permitted the syntax of the quantum theory to determine its "visualizable semantics". By taking into consideration that theory's formal syntax is also constantly embedded in configurations of mathematical practices (thereby being subject to further modifications), the claim that theory's visualizable semantics is entirely determined by the intuitions stemming from this syntax does not seem plausible. The changes of basic mathematical intuitions in the development of quantum mechanics (and more generally, high energy physics) bear witness to the claim that visualizability is not to be isolated from the changing configurations of scientific practices. It is this claim that leads to an extended view of visualizability.

On the leading motif of this view, theoretical objects' visualizability takes place in various spaces of representation and by means of various reading technologies. Thus considered, visualizability is a dimension of the articulation of scientific domains. Each particular configuration of scientific practices in the research process forms a space of representation in which theoretical objects become translated into visible effects (Rheinberger 1997, p. 102). The translation is enabled by the readable technologies of these practices. The theoretical objects are represented by entities ready-to-hand that are intentionally related to invisible dimensions of these objects. The entities ready-to-hand might be material things (e.g. the materialities of a laboratory) or semiotic instruments. Rheinberger points out as a typical experimental representation in molecular biology such in vitro systems of reactions that serve as models for in vivo processes taking place within cells. The way in which the Riemann tensor expresses a configuration of values of the basic set of field quantities that has twenty independent components represents gravity in a formal-quantitative manner 
by measuring the extent to which the metric tensor is not locally isometric to Euclidean space. Let me give also a schematic example of a chain of deferring spaces of representation.

Suppose that one is studying a certain pattern of the dynamics of a kind of complex chemical systems - for instance, the pattern of bifurcations from steady states to oscillations. In this case, the pattern in question is a theoretical object that can be read in several configurations of practices that constitute particular spaces of representation - phase diagrams with independent control parameters; steady state solutions of dynamic equations; experiments with chemical oscillators; descriptions in thermodynamic terms; measurements of amplitude of oscillations at bifurcation point; models of local bifurcations by implementing the so-called Poincar? map; and so on. The upshot of each representation (experimental results, data-models, diagrams, computer simulation, comparative graphics of measurements, modifications of a system of differential equations, and so on) is a possible tool of intervening by means of which a new space of representation comes into play. The theoretical object is dispersed over a range of such spaces, each of them created by readable technologies of scientific practices. In a particular space one is able to actualize certain possibilities of inquiry, neglecting at the same time other possibilities. Thus, there is a constellation of reading, representing, and actualizing possibilities that is of prime importance for hermeneutic realism.

Ex hypothesi the pattern of dynamic behavior of complex chemical systems (as a theoretical object) plays the role of a basic text. Reading this text in various spaces of representation arguably contributes to the articulation of a specific domain of inquiry in physical chemistry. Yet this does not mean that there is a ready-made text given to the interpretative community of readers as a static presence at hand. ${ }^{8}$ At each stage of the research process the text is represented by objects that are ready-to-hand within spaces of representation. In other words, at each stage the space of representation "textualizes" what is under inquiry in a specific manner. The text exists as an ongoing textualizing through readable technologies that constitute spaces of representation.

Initially (at the first stage of textualizing/representing), there is an observation of the rates of change of chemical species concentrations in a homogeneous reacting system. One is preparing reports on how species concentrations in chemical systems (providing feedback) are changing at bifurcation points. This observation becomes "mathematically saved" when the rates of change are read as being governed by a set of coupled, non-linear ordinary differential equations according to the law of mass action. The mathematical text thus achieved is subsequently represented through experimentation with systems that can be displaced from equilibrium by fluxes of matter or energy across its boundaries. A textualizing within experimental systems takes place whereby several types of bifurcation in accordance with the amplitude 
and the period of oscillations at bifurcation point are identified. Each of them is represented by a phase diagram. Designing new instruments and experimental systems enables one to single out those types of bifurcation in which the occurrence of hysteresis is a distinguishing feature. In this regard, a new textualizing/representing of what is under investigation is attained by measuring the value of the bifurcation parameter. Hysteresis is observed when this parameter decreases its past value at which the steady state loses stability. When this occurs, the stable limit cycle persists. Along with this experimental representation, there is a further mathematical textualizing of the manifold of bifurcations from steady state to oscillations. It is related to the search for cases in which the aforementioned dynamic equations admit three steady state solutions promising the identification of new bifurcation patterns. To sum up, there is a unitary process of reading-textualizing taking place in a continuum of deferring spaces of representation - phase diagrams with independent control parameters; steady state solutions of dynamic equations; experiments with chemical oscillators; descriptions in thermodynamic terms; measurements of amplitude of oscillations at bifurcation point; models of local bifurcations by implementing the so-called Poincaré map, etc.

Just because what gets represented/textualized in a certain space is not a static presence-at-hand, it has the potentiality of intervening in the formation of new spaces of representation. This observation enlarges also the meaning of the translational procedure: It refers not only to the way of visualizing theoretical objects by particular configuration of practices, but most of all to the creation of new "traces" and imageries of these objects in further spaces. Here one can get a clear criterion for demarcation between visualization and visualizability that differs essentially from Heisenberg's criterion. Visualization is a momentary and quasi-stable representation of theoretical objects in a space of representation that allegedly is presentat-hand. Visualizability is a potentially endless interplay of visual representations and tools of intervening in deferring spaces that creates "graphemes" of theoretical objects in the articulation of a domain of scientific research. Thus, there is a "permanent gliding replacement" of readiness-to-hand that represents by readinessto-hand that intervenes and vice versa. The extended concept of visualizability I am after refers to the interplay of representing-intervening. Leaning on Derrida, Rheinberger calls the artifacts that visualize theoretical objects "graphemes". ${ }^{9}$ Each theoretical object is a "bundle of graphemes/inscriptions" existing in two forms. First, they are inscribed on horizons of possibilities, thereby indicating the theoretical object's potentiality-for-being. Second, the inscriptions are "traces" and "graphemes" indicating the representing-intervening interplay in applying readable technologies that articulate a domain of scientific research. The traces and graphemes come into being thanks to the appropriation and actualization of possibilities projected upon domain's articulation.

Principia 16(2): 209-227 (2012). 


\section{Conclusion: Hermeneutic Realism and Strong Holism about In- terpretation}

Hermeneutic realism depends strongly on the ontological approach to interpretation. This approach, however, is seriously impeded by a misunderstanding of what the constitutional role of interpretation that takes place in the world's articulation is. I will conclude the present paper by paving the way for overcoming a misconception of the ontological approach to interpretation. In so doing, I will have the chance to get a new angle on the aforementioned constitutional role whose correct elucidation is of prime importance for integrating hermeneutic realism in an appropriate manner in the philosophy of science.

The misconception I am speaking about is typified by James Bohman's view of (what he calls) "strong holism". Let me begin with a short discussion of the distinction between two conceptions of interpretative holism introduced by this author. The first one is described as doomed to an irrecoverable skepticism: The background against which interpretation occurs is an unspecifiable network of practices. By implication, the conflicts of interpretations are undecidable by means of epistemological norms and criteria. On the main tenet of this conception, interpretation is itself indeterminate, contextual, and circular. Given this tenet, the ubiquity of interpretative activity is due to the fact that all cognition's contents are constructed in particular contexts. Accordingly, the argument for the universality of interpretation - so Bohman's line of reasoning goes — states that no cognitive content can be de-contextualized. For this author, strong holism is a conception that maintains the impossibility of specifying such evidential warrants which might constrain interpretative contextuality in a manner that would allow one to employ epistemological norms in adjudicating the acceptability of interpretations. The task of strong holists is to proliferate and multiply interpretations without specifying conditions under which one can establish the validity of any particular interpretation. The "contextualist skepticism" of these hermeneutic philosophers and scholars in the human sciences follows directly from their radically anti-epistemological position. A case in point for Bohman is the neo-Aristotelian insistence on submission to the authority of phronesis-rationality which rejects the primacy of the normative-epistemological rationality.

The second conception (called by Bohman "weak holism") is predicated on the search for holistic conditions for the possibility of interpretation. These conditions set at the same time limits on acts of interpretation. Weak holists are not willing to compromise the holist nature of interpretative procedure by invoking determinate meanings or a non-circular character of interpretation. The task of weak holists is to subject (the various types of) interpretation to normative epistemology. They

Principia 16(2): 209-227 (2012). 
maintain that correctness and validity are the most essential goals of interpretative procedures. The conception of weak holism is first and foremost a transcendental response to skepticism assigned to the attempts at universalizing hermeneutics. The same premises which strong holists call into play are used by this conception to establish a transcendental analysis of interpretation. More specifically, weak holists are supporting a transcendental argument based on these premises concerning the background as a set of shared and accessible conditions of possibility of interpretation. On this argument, interpretation is circular, indeterminate, and perspectival. Furthermore, the background is a transcendental-reflective concept that remains neutral with regard to the warrants of claims about interpretations. Thus, weak holists hold that "interpretations can produce revisable, public knowledge based on evidence." (Bohman 1991, p. 146)

By making use of this argument, they manage to demonstrate that the circularity involved in the epistemic relationship (between background and evidence) of interpretation is non-vicious since it is based on enabling conditions circumscribed by shared practices, stances, and beliefs. What is important for weak holism is the proof (based on the transcendental argument in question) that interpretation is inevitably a comparative, a fallibilistic, and a revisable procedure. In other words, it does not have a special status as compared with the other epistemic procedures entitled to producing theoretical knowledge. The validity and the reliability of interpretations are to be adjudicated by the standard epistemological criteria of objectivity, truthfulness, completeness, coherence, correctness, and so on. By spelling out interpretation in terms of such an epistemic procedure, weak holists oppose the conception of strong holism (and its contextualist skepticism) for its non-reflective account of the background. Like many other philosophers, Bohman is convinced (a) that strong holism is a heading for all versions of the ontological approach to interpretation, and (b) that the distinction he discusses is pertinent to all philosophical profiles of interpretation.

To sum up, Bohman introduces the distinction between weak and strong holism about interpretation as a particular case of the opposition between normative epistemology and "epistemological anarchism" (cum skepticism). In this case, the possibility to unfold cross-contextual claims that promote the formulation of epistemological criteria for resolving crises engendered by the undecidability in the conflicts of interpretations is opposed to the unrestricted proliferation of interpretations in accordance with the dictum "anything goes". My aim now is to show that the concept of interpretation integrated in the doctrine of hermeneutic realism has nothing to do with Bohman's profile of strong holism. Consequently, his distinction is irrelevant to the tenets of hermeneutic realism.

To be sure, interpretation is distinguished by a double status. On the one hand, it is a particular epistemic procedure, epitomized typically by the human sciences' 
interpretative methodology. I agree that the profile of interpretation suggested by Bohman's codification of weak holism matches with the status of interpretation as such a procedure. This profile can be scrutinized in terms of both a transcendental and a normative epistemology. On the other hand, there is (a pre-cognitive) interpretation that takes place in a (trans-subjective) horizon that transcends each possible context circumscribed by a background of shared practices, stances, and beliefs. Thanks to this transcendence, the contextualized existence of human beings is always already open. In its trans-contextuality (transcendence of each possible context, regardless of how strongly it is codified), interpretation is an ontological phenomenon. It is "equipromordial" with phenomena like projection of horizon, potentiality for being, and thrownness in the world of practices. Now, to characterize interpretation in terms of trans-subjectivity and trans-contextuality amounts to defining its status in a completely opposite manner as compared with the manner which follows from Bohman's description of strong holism.

The argument for the universality of interpretation (as ontological phenomenon) does not rest upon the assumption that in each context of the practical being-in-theworld there is an interpretative dimension. It does not rest also on the observation that there is an unlimitable diversification of perspectives in the (contextual) construction of knowledge. Furthermore, the ontological approach to interpretation is not an implication of the alleged impossibility of a normative epistemology of the interpretative activity. The argument for the universality of interpretation which hermeneutic realism puts forward emphasizes in the first place the continuous interplay between contextual-situational finitude and the potential infinity of the aforementioned transcendence. (In another formulation, the interplay between he subjectivity's finitude and the trans-subjectivity's infinity.) It is this interplay which takes on the form of a hermeneutic circle in which all practitioners in the world are always already embedded.

In other words, the hermeneutic circle is not "created" by the human agents. The latter are rather from the outset of their existence involved in this circle (i.e. involved in interpretation that articulates the world of their practices). This is the reason of attributing ontological status to the interpretation which constitutes meaning within the world. On hermeneutic realism, the universality of the (ontologically conceived) hermeneutic circle follows from the situated transcendence of all modes of practical being-in-the world. (Human agents are always at once situated in particular cultural contexts and committed to interpretative horizons that constantly transcend the contexts.) This universality is by no means in a conflict with that transcendentalepistemological approach which constrains interpretation as an epistemic procedure. The ontological argument predicated on the situated transcendence of practical existence is not only foreign to relativist philosophizing, but it is the best argument against relativism: There is no context whose semantic unity and codification can not 
be transcended by interpretative horizon of meaning constitution. ${ }^{10}$ This is also an argument against all kinds of semantic incommensurability employed in cultural anthropology, philosophy of science, cognitive sociology, and several other disciplines. Finally, it is the argument which brings in a most definitive manner the skepticism addressed by Bohman to naught.

\section{References}

Bohman, J.1991. Holism without Skepticism: Contextualism and the Limits of Interpretation. In: D. R. Hiley et al. (eds.) The Interpretive Turn. Ithaca, London: Cornell University Press, pp. 129-54.

Fine, A. 1986. The Shaky Game: Einstein Realism and the Quantum Theory. Chicago, London: University of Chicago Press.

Ginev, D. 1999. From a Strong Hermeneutics of Science to a Strong Rhetoric of Science. Philosophy and Rhetoric 32: 247-81.

- 2003. How to Be Simultaneously an Antiessentialist and a Defender of Science's Cognitive Specificity. Boston Studies in the Philosophy of Science 236: 184-201.

- 2006. The Context of Constitution. Beyond the Edge of Justification. Dordrecht: Springer.

Hacking, I. 1983. Representing and Intervening. Cambridge: Cambridge University Press.

- 1999. The Social Construction of What? Cambridge, Mass.; London: Harvard University Press.

- 1983. Representing and Intervening, Cambridge: Cambridge University Press.

Heelan, P. 1983. Natural Science as Hermeneutic of Instrumentation. Philosophy of Science 50(2): 181-204.

Hendry, J. 1984. The Creation of Quantum Mechanics and the Bohr-Pauli Dialogue. Reidel: Dordrecht.

Miller, A. 1989. Imagery, metaphor, and physical reality. In B. Gholson et al. (eds.) Psychology of Science: Contributions to Metascience, Cambridge: Cambridge University Press, pp. 32641.

Rheinberger, H.-J. 1997. Toward a History of Epistemic Things: Synthesizing Proteins in the Test Tube. Standford: Standford University Press.

Rorty, R. 2007. A pragmatist view of contemporary analytic philosophy. In Philosophy as Cultural Politics. Cambridge: Cambridge University Press, pp. 133-46.

Rouse, J. 1996. Engaging Science. How to Understand Its Practices Philosophically. Ithaca, London: Cornell University Press.

Dimitri GineV University of Sofia Department of Philosophy Tzar Osvoboditel 15 Blvd.

Sofia 1000

Bulgaria dimiginev@yahoo.com

Principia 16(2): 209-227 (2012). 
Resumo. Este artigo explora e tenta resolver algumas questões que surgem quando está em questão a incomensurabilidade entre os conceitos de realidade desenvolvidos pela hermenêutica filosófica, por um lado, e ramos realistas da filosofia analítica, por outro. A concepção do realismo hermenêutico é sugerida não como um remédio contra a incomensurabilidade, mas como um veículo para revisar aqueles aspectos tanto da hermenêutica quanto do realilsmo ontológico que impedem o diálogo entre eles. É uma concepção que se opõe ao fundacionalismo epistemológico, dualismo cartesiano, essencialismo sobre objetos teóricos, e relativismo cognitivo. O papel de ler/textualizar nos espaços de representação da ciência é especificado.

Palavras-chave: Realismo hermenêutico; phronesis-rationalidade; holismo forte; transcendência situada; trans-subjetividade.

\section{Notes}

${ }^{1}$ See on this point Ginev 2003.

2 The doctrine of hermeneutic realism is originally developed by Patrick Heelan (1983). According to him, the reality that is ready to hand in the process of scientific research is constituted as manifolds of meaningful "texts" by means of readable technologies. In this formulation, reading and constitution are intimately related. Texts are not written before initiating a research process. Texts which science reads are artifacts of doing scientific practices, caused to be written by Nature on human instruments within the dynamics of changing configurations of such practices. Hermeneutic realism stresses that reality is always already meaningfully constituted, being thereby a textualized and readable reality. The texts constituted by scientific practices of observation, instrumentation, experimentation, measuring, etc. serve as codes for the perceived objects in normal scientific everydayness.

${ }^{3}$ A detailed treatment of the core-doctrines of hermeneutic realism is suggested in Ginev 2006.

${ }^{4}$ On the main interventionist argument, it is the causal efficacy achieved by interventions through experimentation (and explanatory power) that demands realism. In this perspective, science's theoretical objects are understood as tools to intervene in nature. Interventionism is after a practical basis for realism about theoretical objects.

${ }^{5}$ Hacking 1983, p. 263. On interventionist realism, it is causal efficacy achieved by interventions through experimentation (and explanatory power) that demands realism. In this perspective, science's theoretical objects are understood as tools to intervene in nature, constructing thereby new phenomena. Interventionist realism is after a practical basis for realism about theoretical objects. In his later work, in re-reading Nelson Goodman's view of kind-making, Hacking goes on to claim that there is nothing wrong in claiming that something can be both real and a social construction. (See Hacking, 1999, pp. 125-162.) I agree. However, one can only make sense of this claim against the background of the view that the real is socially constructed within-the-world, and "the world" is reducible neither to objective reality nor to the outcome of the processes of social construction.

${ }^{6}$ There is an important consequence following from this claim, which I would like to indicate in a tentative manner: A theory of scientific research's situated transcendence has a priority over the rational reconstructions of science's historical dynamics in terms of normative epistemology.

Principia 16(2): 209-227 (2012). 
${ }^{7}$ See Hendry 1984, pp. 111-5. Notoriously, Heisenberg's appeal to dispensing as much as possible with visual pictures in quantum mechanics draws on the distinction between a measurement and an observation. More specifically, it is closely related to the rejection of the assumption that there is no measurement devoid of an observable result. The disturbance of a magnitude (position, momentum, energy, time) generated by a measurement (as controlled by the uncertainty relations) dissociates strongly observed measurements (and their visual pictures) from unobserved measurements: The wave picture (and the probabilities one can assign to future events) depend on whether one observes the result of measurement. Heisenberg assumes also that the rule of visualization coincides with the rule of unlimited observability.

${ }^{8}$ According to the position advocated in the foregoing considerations, to read a text in a space of representation constituted by scientific practices amounts to constructing a text by means of configured readable technologies. The text is at once already there as something that is present-at-hand, and something that arises out of deferring representations dispersed over an expanding network of readable technologies. What becomes textualized is ready-tohand in the same manner in which the readable technologies are not detachable from the interpretative community of readers. Only research objects that are ready-to-hand are readable objects. However, one should attribute to the objects described in scientific publications a status of entities that are present-at-hand. This can only be achieved by using appropriate rhetoric - the rhetoric of presenting an ongoing readiness-to-hand as a presence-at-hand. By raising this claim I am entering the territory of the rhetorical studies of science. (See on this point Ginev 1999.)

${ }^{9}$ In this perspective, the articulation of a domain of scientific research takes on the form of "graphematic articulation (Rheinberger 1997, p. 111). The graphemes articulate the domains of scientific research as systems of signification within spaces of representation. Rheinberger makes it clear, however, that there is no space of representation prior to an articulation of graphemes. In this articulation, an ongoing proliferation of visualizable traces of theoretical objects takes place.

${ }^{10}$ Human beings are interpretative creatures not because in their contextualized cognition they do not have facts, but only interpretations. Human beings are such creatures since all particular contexts of cognition are interpretatively fore-structured by trans-subjective horizons.

Principia 16(2): 209-227 (2012). 